\title{
Normative data of multifrequency tympanometry in rabbits
}

\section{Martin Stieve*, Hans Hedrich ${ }^{\dagger}$, Hamidreza Mojallal*, Peter Behrens ${ }^{\ddagger}$, Peter Müller§ and Thomas Lenarz*}

${ }^{\star}$ Department of Otorhinolaryngology, Medical University of Hannover, Carl-Neuberg-Strasse 1, DE-30625 Hannover, Germany; ${ }^{\dagger}$ Department of Laboratory Animal Science, Hannover Medical School, Hannover, Germany; ${ }^{\ddagger}$ Institute of Inorganic Chemistry, University of Hannover, Hannover, Germany; $\S^{\S}$ German Research Centre for Biotechnology, Braunschweig, Germany

\section{Summary}

In an experimental study, we evaluated acoustic immittance in rabbits in order to use these data as normative values for further experimental investigations. This study is the first experimental evaluation of both conventional $226 \mathrm{~Hz}$ and multifrequency tympanometry (MFT) in rabbits. For the investigation, we used 33 female New Zealand rabbits weighing 3.2$4.4 \mathrm{~kg}$ and aged six months. Bilateral measurements using conventional $226 \mathrm{~Hz}$ and MFT were performed under general anaesthetic. A $226 \mathrm{~Hz}$ tympanogram was recorded for all animals by conducting an air pressure sweep from +200 to $-400 \mathrm{daPa}$ at a rate of $50 \mathrm{daPa} / \mathrm{s}$. Subsequent tympanograms were recorded over a wide frequency range from 250 to $2000 \mathrm{~Hz}$. The acoustic impedance device used in this study provided reproducible and evaluable tympanograms. The applied tone frequency of $226 \mathrm{~Hz}$ proved to be especially suitable for determining compliance. Normative data obtained from our study reveal the resonance frequency to be $1368 \pm 205$ standard deviation (SD) for the right side and $1413 \pm 216 \mathrm{SD}$ for the left side. The values for physiological acoustic immittance of the middle ear in the rabbit obtained here can serve as normative data in subsequent experimental animal studies.

Keywords Animal model; organisms and models; multifrequency tympanometry; acoustic immittance; white rabbit

Tympanometry at $226 \mathrm{~Hz}$ has become a routine clinical measure for evaluating the acoustic immittance of the middle ear. Tympanometry is suitable for detecting middle ear disorders, such as otitis media, an interrupted ossicular chain and defects of the tympanic membrane. Multifrequency tympanometry (MFT) is a technique for evaluating the immittance of the middle ear over a wide frequency range.

In the field of experimental evaluation, MFT has been shown to be useful for monitoring diseases in certain animal studies (Margolis 1995, Cole \& Kwochka 2000, Hsu

Correspondence: $M$ Stieve.

Email: stieve.martin@mh-hannover.de

Accepted 3 August 2007 et al. 2000). Margolis $(1995,1998)$ performed MFT on normal chinchillas and Mongolian gerbils in order to obtain normative data against which to compare results obtained from animals with middle ear pathology. They induced different diseases and measured the resonance frequency; their interventions included artificially extending the ear canal, inducing serous otitis media and disrupting the ossicular chain. The results are similar to those in healthy human subjects and patients with middle ear diseases.

In this study, we intended to define normative values serving as the basis for further experimental studies on the middle ear of the rabbit. Particularly in experimental otology, the middle ear of the rabbit has become the 
standard model for the development of new prostheses replacing the ossicular chain. While normative values of inner ear function do exist, findings concerning middle ear function are insufficient.

This study is the first experimental evaluation of both conventional $226 \mathrm{~Hz}$ and MFT in rabbits. Based on the results of the experimental examinations, reference values were established for both physiological tympanograms and resonance frequency.

\section{Methods}

\section{Animals}

This experimental animal study involved a total of 33 approximately six-month-old New Zealand white female rabbits originating from the Charles River animal breeding farm (Sulzfeld, Germany). The selection of the species was based on its similarity to human middle ear anatomy and the standardized, microsurgical approach to the tympanic cavity that is favoured (Steinbach 1973).

The animals had a body weight of between 3.2 and $4.4 \mathrm{~kg}$. They were housed in individual cages in a climate-controlled room at the Medical University of Hannover's Central Animal Laboratory. The cages measured around $50 \times 60 \times 45 \mathrm{~cm}$ in size, with a floor consisting of a perforated metal plate. They were equipped with a nipple drinking system providing the animals with water ad libitum. The rabbits received $100 \mathrm{~g}$ of a pelleted, all-in-one food (SSNIFF, Soest, Germany) and $150 \mathrm{~g}$ of autoclaved straw daily. The temperature in the room was around $20 \pm 2^{\circ} \mathrm{C}$, with humidity at $55 \pm 5 \%$. The animals were kept under an artificially controlled, $12 \mathrm{~h}$ light/dark cycle.

\section{Anaesthetic management}

All measurements were performed under inhalation anaesthetic. Anaesthesia by intubation has crucial advantages over anaesthesia by barbiturates. The depth of anaesthesia can be better controlled, enabling mortality to be considerably reduced (Lipman et al. 1997).
Prior to anaesthesia, each animal was examined as to its general condition in order to eliminate the risk of anaesthetic complications. Body weight was determined in order to allow precise individual dosage of the medication. Two premedication drugs were applied intramuscularly: $25 \mathrm{mg} / \mathrm{kg}$ of ketamine (Ketanest ${ }^{\circledR}$; Albrecht $\mathrm{GmbH}$ and Co KG, Aulendorf/Württemberg, Germany) and $5 \mathrm{mg} / \mathrm{kg}$ of midazolam hydrochloride (Midazolam ${ }^{\circledR}$; CuraMed Pharma GmbH, Hameln, Germany). Anaesthesia was induced by applying the short-acting anaesthetic agent Propofol-Lipuro 1\% (Propofol ${ }^{\circledR}$; B Braun Melsungen AG, Melsungen, Germany) at a dosage of $1 \mathrm{mg} / \mathrm{kg}$, into the auricular vein of the left ear via an indwelling venous catheter $(0.9 \mathrm{~mm} \times 25 \mathrm{~mm}$; B Braun Melsungen AG). Glycopyrrolate 5 mg (Robinul ${ }^{\circledR}$; Riemser Arzneimittel AG, Riems Island, Germany) was then administered intramuscularly, with $5 \mathrm{mg}$ of buprenorphine hydrochloride (Temgesic ${ }^{\circledR}$; Essex Pharma GmbH, Munich, Germany) administered subcutaneously. Following endotracheal intubation, narcosis was maintained with $1.5 \%$ isoflurane $\left(\right.$ Forene ${ }^{\circledR}$; Abbot GmbH, Wiesbaden, Germany). An infusion of $10 \mathrm{~mL} / \mathrm{kg} / \mathrm{h}$ of SterofundinHEG-5 (B Braun Melsungen AG) was used to stabilize the circulatory system of the animals. In order to ensure that decreasing body temperature did not influence the derivates, the body temperature of the animals (taken rectally) was stabilized at $39 \pm 0.5^{\circ} \mathrm{C}$ using a heating mat on which the rabbits were placed in prone position. To avoid temperature variations, an additional red-light heating lamp was activated when the temperature fell by $>0.5^{\circ} \mathrm{C}$. Temperature readings were taken continuously throughout the experimental period. Anaesthesia was performed using a semiopen anaesthetic machine (Dräger Medical $\mathrm{AG}$ and Co KGaA, Lübeck, Germany) and maintained using a mix of isoflurane (Forene ${ }^{\circledR}$; Abbot $\mathrm{GmbH}$ ) and oxygen (1.5\%) $1.5 \mathrm{~L} / \mathrm{min}$ on average). Once the measurements had been completed, the animals were immediately euthanized using $3 \mathrm{~mL}$ of pentobarbital administered intravenously (Eutha $77^{\circledR}$; Pitmann-Moore, Inc, 
Washington, USA) while still under anaesthetic.

\section{Auditory assessments}

Tympanometry was performed using the GSI 33 Version 2 tympanometer (Grason-Stadler, Inc, Littleton, USA). The system is capable of recording tympanograms from 226 to $2000 \mathrm{~Hz}$ at $1 / 6$ octave intervals. The complexity of the ear canal acoustics does not permit accurate calibration above $2000 \mathrm{~Hz}$. The probe was hermetically sealed in the ear canal close to the osseous border, a standard clinical probe being used. A $226 \mathrm{~Hz}$ tympanogram was recorded for all animals by conducting an air pressure sweep from +200 to $-400 \mathrm{daPa}$ at a rate of $50 \mathrm{daPa} / \mathrm{s}$. The following tympanograms were recorded over a wide frequency range from 250 to $2000 \mathrm{~Hz}$. The immittance values thus recorded were computer-processed to provide standard MFT curves. The computer analysed resonance frequency, generating a diagram in which $\Delta B$ is 0 (Figure 1).

In order to establish the ideal probe-tone frequency for recording the tympanograms, we took repeat measurements at different frequencies $(226,678$ and $1000 \mathrm{~Hz})$.

\section{Microscopic examination}

A microscopic examination of the middle ear was carried out in order to ensure that no fluid (or any other pathological change) had led to a distortion of the measured data. The most reliable method is therefore the direct removal of the temporal bones and subsequent microscopic examination.
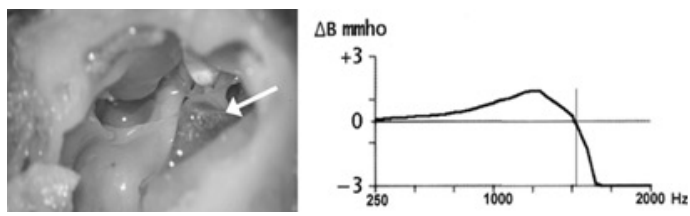

Figure 1 Middle ear (left) following preparation and opening. Ossicles (white arrow indicates the tympanic membrane) and mucosa non-inflamed. Multifrequency tympanogram (right) as an example illustrating the determination of the resonance point. $(\Delta \mathrm{B}=0)$
Assessment under the surgical microscope was carried out immediately following euthanasia and preparation of the temporal bones (with opening of the tympanic bulla). The ossicular chain and surrounding tissue were microscopically examined for increased vascularization and new tissue formation. Tweezers were used to move the eardrum slightly so that, in the functional test, the coupling of the ossicular chain to the surrounding structures could be assessed.

\section{Statistical analysis}

For all recorded data, the arithmetic mean, standard deviation (SD), median and minimum and maximum values were calculated. Data were tested for normal distribution using the Kolgomorov-Smirnov and Anderson-Darling goodness-of-fit tests. The Wilcoxon signed-rank test was used to calculate the significance levels $(P)$ of the measured data obtained. The statistical program used was Statistical Analysis System (SAS Institute, Inc, Cary, USA).

\section{Results}

Overall, performing tympanograms using the GSI 33 Version 2 tympanometer proved straightforward. The probe-tone frequencies can be used in the rabbit in the same way as with the human middle ear, so that tympanograms could be recorded in $100 \%$ of cases. One drawback was the lack of a means of electronically storing the data, hence a written record had to be maintained.

\section{$226 \mathrm{~Hz}$ tympanometry}

Using probe-tone frequencies of 226, 678 and $1000 \mathrm{~Hz}$ for the repeat measurements,

Table 1 Average physiological compliance $(\mathrm{mL})$ for both ears, as measured by conventional tympanometry using a $226 \mathrm{~Hz}$ probe tone

\begin{tabular}{lll}
\hline & Right side & Left side \\
\hline Mean & 0.18 & 0.17 \\
Median & 0.2 & 0.2 \\
Range & $0.1-0.3$ & $0.1-0.3$ \\
Standard deviation & 0.06 & 0.06 \\
Number & 33 & 33 \\
$P$ & $>0.05$ & $>0.05$ \\
\hline
\end{tabular}


Table 2 Average physiological amplitude pressure (daPa) for both ears, as measured by conventional tympanometry using a $226 \mathrm{~Hz}$ probe tone

\begin{tabular}{lll}
\hline & Right side & Left side \\
\hline Mean & -35.61 & -35.6 \\
Median & -50 & -45 \\
Range & $-115-25$ & $0.1-0.3$ \\
Standard deviation & 35.24 & 35.2 \\
Number & 33 & 33 \\
$P$ & $>0.05$ & $>0.05$ \\
\hline
\end{tabular}

adequate tympanograms were obtained, with the highest degree of reliability achieved at $226 \mathrm{~Hz}$. Tables 1 and 2 present the values for compliance (mean and SD) and amplitude pressure for both ears. None of the statistical analyses performed revealed any significant differences $(P>0.05)$ for the compliance values determined from the tympanogram. Trends in the median values revealed almost no dependence on the time of measurement for either the left or the right ear.

\section{Multifrequency tympanometry}

In our studies, the success rate in determining the resonance point was $100 \%$. Normative data obtained from our study reveal the resonance frequency to be $1368 \pm 205$ for the right side and $1413 \pm 216$ for the left side (Table 3). The maximum value recorded for the right ear was 1750 and the mimimum was 1050. On the left side, the maximum was 1800 and the minimum was 1000 .

\section{Microscopic examination}

Following euthanasia and removal of the temporal bones, the bulla was opened and the tympanic cavity was examined under the microscope. In all the test animals, the site showed no sign of irritation, fluid

Table 3 Average physiological resonance frequency $(\mathrm{Hz})$ for both ears, as measured by multifrequency tympanometry

\begin{tabular}{lll}
\hline & Right side & Left side \\
\hline Mean & 1368.1 & 1413.8 \\
Median & 1350 & 1400 \\
Range & $1050-1750$ & $1000-1800$ \\
Standard deviation & 205.5 & 216.4 \\
Number & 33 & 33 \\
$P$ & 0.47 & 0.47 \\
\hline
\end{tabular}

accumulation or inflammation. In two animals, accumulations of viscous fluid were observed, indicating seromucous otitis media. These animals were removed from the study.

\section{Anaesthetic}

Four rabbits died in the initial phase during the anaesthesia procedures carried out as part of the preparatory work. Autopsies performed on the deceased animals suggested vagal cardiac arrest. As a result, the anaesthesia regimen was augmented by the anticholinergic agent Robinul ${ }^{\circledR}$, dosed at $5 \mathrm{mg} /$ animal in the form of an intramuscular injection.

\section{Discussion}

Whereas, in the field of animal experimentation, normative values for MFT exist for species such as the chinchilla and Mongolian gerbil (Margolis 1995, 1998), no data on the resonance behaviour of the rabbit middle ear can currently be found in the literature. However, the anatomical situation is described in detail and surgical access routes exist, which allow experimental implantation of the newly developed ossicular prostheses.

Tympanometry is a non-intrusive method and can be performed under sedation. Intubation anaesthesia, as used in this study, has the advantage of allowing better control while registering the vital parameters.

The tympanometer employed in this study (GSI 33, Version 2) has already been successfully used by Cole and Kwochka (2000) to obtain tympanograms in dogs. It has the advantage of allowing both conventional and MFT to be performed. In the present study, the machine was successfully tested for use in rabbits. We recorded $100 \%$ diagnostically usable tympanograms. Now that the device has been refined for use in human medicine, the scale of the tympanogram is tailored to humans. For use in rabbits, it would be helpful to be able to individualize this scale, so that lower compliance values could be shown more clearly. 


\section{$226 \mathrm{~Hz}$ tympanometry}

Various probe-tone frequencies $(226,678$ and $1000 \mathrm{~Hz}$ ) were tested in the present study. In their investigations, Counter et al. (1989) report that they failed to obtain adequate tympanograms in rabbits at a probe-tone frequency of $226 \mathrm{~Hz}$. In the present authors' own study, however, tympanograms with comparable curves were obtained at all three of the frequencies used. In the present investigation, therefore, following the recommendation by Kiessling (1982), a probetone frequency of $226 \mathrm{~Hz}$ was used in order to minimize the influence of the factors of friction and mass and thus determine the compliance as precisely as possible.

\section{Amplitude pressure}

In our studies, amplitude pressure was between 0 and $-100 \mathrm{daPa}$, thus falling within the normal range for data in human medicine (Shahnaz \& Polka 1997, Miani et al. 2000, Lehnhardt \& Laszig 2001). The pressure fluctuations observed in the rabbit are, however, still within the tolerance range of $100 \mathrm{daPa}$. A comparison of both ears produced no statistically significant differences. A possible explanation for the negative amplitude pressure measured in several rabbits could be seen in the animals' failure to swallow while under anaesthetic. This may lead to the formation of negative pressure in the middle ear, as the air is reabsorbed via the mucous membranes of the middle ear and no air can subsequently flow in via the closed tube. Cole and Kwochka (2000) also report changes to the tympanogram during lengthy anaesthesia in dogs.

In order to ensure that the inhalation anaesthetic agent was unable to influence the amplitude pressure, we used isoflurane. Both halothane and nitrous oxide (laughing gas) are reported in the literature as influencing amplitude pressure, whereas no such effects are observed when isoflurane is used (Kuschnir et al. 1981, Lawrence et al. 1994). The increase in amplitude pressure is attributed to the accumulation of laughing gas in closed cavities through direct exchange with the nitrogen in the air.

\section{Compliance}

Compliance values are considerably lower than those for the human middle ear, which supports the findings of Rosowski (1994). The reason for this is the greater stiffness of the rabbit middle ear. As compliance is the inverse of stiffness, a stiff eardrum has a lower compliance, whereas a flaccid eardrum leads to a higher compliance (Lehnhardt \& Laszig 2001).

\section{Multifrequency tympanometry}

The physiological resonance point for the rabbit ear was found to average $1368.1 \mathrm{~Hz}$ (preoperative, right ear), which is higher than in humans $(974 \mathrm{~Hz})$. The significant differences are mainly due to the different size and the corresponding functional effects.

According to Schönfelder et al. (1990), the surface area of the tympanic membrane and the base of the stapes, as well as the length of the incus, are nearly twice as great as in the rabbit. This results in different leveraging interactions which affect the biomechanics of the tympanic membrane and ossicles. The different surface ratios of the tympanic membrane and stapes, as well as the leveraging effect of the manubrium of the malleus and the incus, result in a total amplification factor of 48.6 as opposed to 21.4 in humans (Lehnhardt \& Laszig 2001). The increased rigidity of the system results in the resonance point shifting to a higher part of the frequency range.

MFT is suitable for evaluating the immittance of the middle ear. The results will serve as normative values for future experimental studies.

Acknowledgement This project is supported by the German Research Foundation (DFG) within the collaborative research programme SFB 599/D1.

\section{References}

Cole LK, Kwochka KW (2000) Impedance audiometry measurements in clinically normal dogs. American Journal of Veterinary Research 61, 442-5

Counter SA, Borg E, Engström B (1989) Acoustic middle ear reflexes in laboratory animals using clinical equipment: technical considerations. Audiology 28, 135-43

Kiessling J (1982) Impedanzaudiometrie in der HNO Fachpraxis. In: HNO Praxis Heute (Ganz H, Schätzle W, eds). New York: Springer-Verlag, 5-26 
Kuschnir H, Rust M, Eisler K (1981) Druckmessungen im mittelohr bei unterschiedlichen narkoseverfahren. Laryngo-Rhino-Otologie 60, 418-20

Lawrence T, Francis F, Marsh RR, Kessler A, Kinkle DF (1994) Effect of aneaesthetic gas on middle ear fluid. Laryngoscope 104, 832-6

Lehnhardt E, Laszig R (2001) Praxis der Audiometrie. Stuttgart, New York: Georg Thieme

Lipman NS, Marini RP, Flecknell PA (1997) Anesthesia and analgesia in rabbits. In: Anesthesia and Analgesia in Laboratory Animals. American College of Laboratory Animal Series (Kohn DF, Wixson SK, White WJ, Benson GJ, eds). San Diego: Academic Press, 2005-232

Hsu GS, Margolis RH, Schachern PL (2000) Development of the middle ear in neonatal chinchillas. I. Birth to 14 days. Acta Otolaryngologica 120, 922-32

Margolis RH, Schachern PL, Hunter LL, Sutherland C (1995) Multifrequency tympanometry in chinchillas. Audiology 34, 232-47

Margolis RH, Schachern PL, Fulton S (1998) Multifrequency tympanometry and histopathology in chinchillas with experimentally produced middle ear pathologies. Acta Otolaryngologica 118, 216-25

Miani C, Bergmamin AM, Barotti A, Isola M (2000) Multifrequency multicomponent tympanometry in normal and otosclerotic ears. Scandinavian Audiology 29, 225-37

Rosowski J (1994) Outer and middle ears. In: Comparatitive Hearing in Mammals (Fay R, Popper A, eds). New York: Springer-Verlag, $172-237$

Schönfelder J, Rother P, Zschäckel M (1990) Morphologische Untersuchungen über die postnatale Veränderungen des Schallantransportapparates im Mittelohr bei Mensch und Kaninchen. Anatomische Anzeiger 170, 213-19

Shahnaz N, Polka L (1997) Standard and multifrequency tympanometry in normal and otosclerotic ears. Ear and Hearing 18, 326-40

Steinbach E (1973) Vergleichende Untersuchungen an Gehörknöchelchen und Knochentransplantaten beim Kaninchen und Menschen. Medizinische Fakultät Tübingen Habilitationsschrift, 31-2 